\title{
UJI EFEKTIVITAS EKSTRAK BUAH LEUNCA (SOLANUM NIGRUM L.) SEBAGAI INSEKTISIDA TERHADAP NYAMUK AEDES AEGYPTI DAN ANOPHELES ACONITUS
}

\author{
Reisya Tiara Kandita, ${ }^{1}$ Riandini Aisyah, ${ }^{2}$ Wulandari Berliani Putri ${ }^{2}$ \\ 1. Student of Faculty of Medicine, Universitas Muhammadiyah Surakarta \\ 2. Lecture of Faculty of Medicine, Universitas Muhammadiyah Surakarta \\ Korespondensi: Riandini Aisyah \\ Email: riandini@ums.ac.id
}

\begin{abstract}
ABSTRAK
Nyamuk Aedes aegypti dan Anopheles aconitus merupakan beberapa vektor penting pada penyakit tropis di Indonesia, antara lain seperti penyakit demam berdarah dan malaria. Salah satu cara pemberantasan nyamuk yang paling sering digunakan adalah dengan menggunakan insektisida. Penggunaan insektisida kimiawi yang bertujuan untuk membunuh nyamuk dewasa juga menimbulkan permasalahan tersendiri yaitu timbulnya resistensi nyamuk dan efek toksik pada manusia. Oleh karena itu, diperlukan insektisida alternatif yang lebih aman terhadap lingkungan yang berasal dari tanaman. Salah satunya dengan menggunakan ekstrak buah Leunca (Solanum nigrum). Buah Leunca mengandung glikoalkaloid yang beracun. Penelitian ini bertujuan untuk membuktikan ekstrak buah Leunca mempunyai potensi sebagai insektisida alami terhadap nyamuk Aedes aegypti dan Anopheles aconitus. Penelitian ini merupakan penelitian eksperimental laboratoris dengan rancangan true experimental-post test only control group design. Sampel yang digunakan adalah nyamuk Aedes aegypti dengan konsentrasi ekstrak 20\%, 40\%, 60\%, dan 80\% dan nyamuk Anopheles aconitus dengan konsentrasi ekstrak 5\%, 10\%, 20\% dan 40\%. Dilakukan penyemprotan pada glass chamber kemudian diamati sampai 20 menit, setelah itu nyamuk dipindah ke dalam paper cup dan diamati selama 24 jam. Pengulangan dilakukan sebanyak empat kali. Uji yang digunakan adalah uji Oneway Anova dengan nilai $p<0,05$ dan analisis probit.Hasil uji Oneway Anova diperoleh nilai signifikansi < 0,05. Hasil penelitian menunjukkan bahwa ekstrak buah Leunca memiliki efek insektisida terhadap nyamuk Aedes aegypti dan Anopheles aconitus. Hasil analisis probit nyamuk Aedes aegypti LC50 terletak antara 69,890\% dan 156,417\% dengan estimasi 91,128\% dan LC90 terletak antara 337,934\% dan 5842,532\% dengan estimasi 785,398\%, sedangkan nyamuk Anopheles aconitus LC50 terletak antara 19,809\% dan 33,570\%. dengan estimasi 24,767\% dan LC90 terletak antara 96,540\% dengan 450,875\% dengan estimasi 169,046\%. Peneliti menyimpulkan bahwa ekstrak buah Leunca (Solanum nigrum L.) memiliki efek insektisida terhadap nyamuk Aedes aegypti dengan konsentrasi 80\% dan Anopheles aconitus dengan konsentrasi 40\%.
\end{abstract}

Kata Kunci: Ekstrak buah Leunca (Solanum nigrum), insektisida, Aedes aegypti, Anopheles aconitus

\begin{abstract}
Aedes aegypti and Anopheles aconitus are some of important vectors in Indonesian tropical disease such as yellow and malaria. One way to eradicate mosquitoes that most commonly used is to use insecticides. The use of chemical insecticides which isaimed to kill the adult mosquitous also poses its own problems thatis the emergence of mosquitoes resistance and toxic effects in humans. Therefore, there are alternative insecticides from plant required, which is environmentally friendly. One of them is the extract of Leunca (Solanum nigrum) as it contains poisonous fruits glycoalkaloids. This study aimedto prove that Leunca fruit extracts has potential as an insecticide against Aedes aegypti and Anopheles aconitus mosquitoes. This research is a laboratory experimental research with true experimental post test only control group design. The samples were Aedes aegypt mosquitoes with extract concentrations used were 20\%, 40\%, 60\%, and 80\% and Anopheles aconitus mosquitoes with extract concentrations used were 5\%,10\%, 20\% and 40\%. Did sprayed on glass chamber and observed until 20 minutes, then moved the mosquitoes on paper cup and observed for 24 hours. Repeatition was done forfour times.
\end{abstract}


The statistic test used Oneway Anova test with $p$ value $<0,05$ and probit analysis. The result of Oneway Anova shows that the significancy value is $<0,05$. It means that Leunca fruit extracts have insecticide effect to Aedes aegypti and Anopheles aconitus mosquitoes. From probit analysis of Aedes aegypti mosquitoes, $L C_{50}$ is between $69,890 \%$ and $156,417 \%$ with estimation $91,128 \%$ and $L C_{90}$ is between $337,934 \%$ and $5842,532 \%$ with estimation 785,398\%. While the Anopheles aconitus, $L C_{50}$ is between 19,809\% and 33,570\% with estimation 24,767\% and $L C_{90}$ is between $96,540 \%$ and $450,875 \%$ with estimation 169,046\%. We conclude that Leunca (Solanum nigrum L.) fruit extracts has insecticide effect to Aedes aegypti mosquitoes with concentration $80 \%$ and Anopheles aconitus with concentration $40 \%$.

Keywords: Leunca (Solanum nigrum) fruit extracts, insecticide, Aedes aegypti, Anopheles aconitus

\section{PENDAHULUAN}

Demam Berdarah Dengue (DBD) adalah suatu penyakit demam akut yang disebabkan oleh infeksi Flavivirus yang ditularkan melalui gigitan nyamuk Aedes aegypti (Irwadi et.al., 2007). Nyamuk Aedes aegyptiaktif menghisap darah pada pagi hari dan sore hari. Di beberapa daerah nyamuk Aedes aegypti memperlihatkan perubahan perilaku yaitu adanya aktivitas menghisap darah pada malam hari (nokturnal) (Hadi et.al, 2012). Pada tahun 2011 tercatat angka kejadian DBD per 100.000 penduduk di berbagai kabupaten, yaitu Semarang (3,76), Purworejo $(27,79)$, Jepara $(23,3)$, Demak (20,75), Kudus (19,04), Karanganyar $(14,44)$, Sukoharjo $(12,98)$, Klaten $(9,2)$, Cilacap $(8,95)$, Blora $(7,71)$ (Dinkes Jawa Tengah, 2011).

Malaria merupakan penyakit yang disebabkan oleh Plasmodium sp. yang menyerang eritrosit dan ditransmisikan dalam alam melalui orang ke orang oleh gigitan nyamuk Anopheles(Freedman, 2008). Nyamuk Anopheles aktif menggigit sepanjang malam dan menjelang pagi hari. Data WHO menyebutkan tahun 2010 di Indonesia terdapat 544.470 kasus(Depkes RI, 2011). Angka kejadian per 1000 penduduk pada tahun 2011 adalah 1,75\% sedangkan tahun 2012 menurun menjadi 1,69\%(Depkes RI, 2013). Perubahan perilaku tersebut berpotensi meningkatkan kepadatan larva dan kepadatan nyamuk yang mempunyai risiko transmisi nyamuk yang cukup tinggi untuk terjadi penularan penyakit. Upaya pemberantasan vektor dapat menggunakan senyawa kimia yang memberikan dampak cepat dalam memutus siklus penularan, namun senyawa kimia sintetik dapat menyebabkan sifat resisten pada nyamuk dan menimbulkan masalah bagi lingkungan(Astuti, 2008).

Cara pengendalian alamiah yang dapat dilakukan adalah menggunakan insektisida berbahan dasar dari tumbuhan dan mengandung bahan kimia (bioactive compound) yang toksik terhadap serangga tetapi mudah terurai (biodegradable)di alam sehingga tidak mencemari lingkungan, relatif aman dan bersifat selektif(Lailatul et.al, 2010).

Salah satu tanaman yang dapat dimanfaatkan adalah tanaman Leunca (Solanum nigrum L.) yang mengandung glikoalkaloid pada buah muda yang besifat racun ${ }^{3}$. Dua racun utama pada glikoalkaloid, yaitu solanin dan chaconin. Kadar glikoalkaloid yang tinggi dapat menimbulkan rasa pahit dan keracunan pada hewan maupun manusia (Badan POM RI, 2008).

Berdasarkan uraian di atas, peneliti ingin meneliti apakah ekstrak buah Leunca (Solanum nigrum L.) mempunyai efek insektisida terhadap nyamuk Aedes aegypti dan Anopheles aconitus, mengingat buah Leunca (Solanum nigrum L.) mengandung glikoalkaloid yang beracun.

\section{METODE}

Jenis penelitian adalah true experimentalpost test only control group design. Subyek yang digunakan dalam penelitian ini adalah nyamuk dewasa Aedes aegyti dan Anopheles aconitus yang hidup dan aktif bergerak yang diperoleh dari Balai Besar Penelitian dan Pengembangan Vektor dan Reservoir Penyakit (B2P2VRP) di Salatiga, Jawa Tengah. Metode penelitian insektisida dilakukan dengan cara menyemprotkan ekstrak buah Leunca (Solanum nigrum L.) pada nyamuk Aedes aegypti dan Anopheles aconitus dengan konsentrasi 5\%, $10 \%, 20 \%$ dan $40 \%$.

\section{Alat dan bahan}

\section{Alat}

Alat yang digunakan dalam penelitian ini 
adalah sangkar kaca berbentuk bujur sangkar berukuran $25 \times 25 \times 25 \mathrm{~cm}^{3}$, stopwatch, gelas ukur, sprayer, sspirator, pipet, termometer ruangan, hygrometer.

\section{Bahan}

Bahan yang digunakan dalam penelitian ini adalah ekstrak buah Leunca konsentrasi 1,25\%, $2,5 \%, 5 \%$ dan $10 \%$, bahan penyari yaitu etanol $70 \%$, aquades steril, nyamuk dewasa Aedes aegypti dan Aedes albopictus yang hidup dan aktif bergerak.

\section{Cara kerja}

a. Sebelum pengujian

Glass chamber dibersihkan agar tidak terkontaminasi oleh insektisida lain, dengan cara (1) bagian dalam glass chamber dicuci sampai bersih dengan lap basah yang mengandung cairan deterjen, (2) glass chamber dibilas dengan lap basah tanpa deterjen, dan (3) glass chamber dikeringkan dengan lap basah tanpa deterjen.

b. Uji pendahuluan

1). Nyamuk Aedes aegypti dan Anopheles aconitus dilepaskan dalam glass chamber dengan aspirator sebanyak 25 ekor dan ditunggu selama 1 menit, dicatat temperatur ruangan glass chamber.

2). Ekstrak buah Leunca (Solanum nigrum L.) disemprotkan pada konsentrasi yang telah ditentukan, jumlah semprotannya sesuai hasil peneraan kadar semprotan (Y kali semprotan). Kontrol disemprot dengan pelarut (aquades) sebanyak $\mathrm{Y}$ kali semprotan. Cara perhitungan sebagai berikut:

a). Alat semprot yang telah diisi ekstrak buah Leunca (Solanum nigrum L.) ditimbang, misal A gram.

b). Disemprotkan alat semprot secara maksimal sebanyak 10 kali.

c). Alat semprot dan ekstrak buah Leunca (Solanum nigrum L.) ditimbang kembali (B gram).

d). Langkah 2 dan 3 diulangi 3 kali (C gram dan $\mathrm{D}$ gram), selanjutnya selisih berat setiap ulangan dirata-rata.

Dihitung jumlah ekstrak buah Leunca
(Solanum nigrum L.) yang diperlukan untuk pengujian.

$\begin{aligned} & \text { Berat } 1 \text { kali } \\ & \text { semprotan }\end{aligned}=\frac{(\mathrm{A}-\mathrm{B})+(\mathrm{B}-\mathrm{C})+(\mathrm{C}-\mathrm{D})^{*}}{3 \text { ulangan x } 10 \text { semprotan }}=\mathrm{X}$ gram

Jumlah semprotan ekstrak buah Leunca (Solanum nigrum L.) yang diperlukan adalah : 0,70 gram $* *: X$ gram $=\mathrm{Y}$ kali semprotan.

Keterangan :

* : Selisih setiap ulangan pemeriksaan harus $<0,2$ gram

** : Dosis standart digunakan di UPKV / USM Malaysia

3). Diamati selama 20 menit, hitung dan catat nyamuk pingsan atau mati setiap periode waktu yang telah ditentukan.

4). Semua nyamuk dipindahkan dengan aspirator ke dalam paper cup dan disimpan dalam holding selama 24 jam. Beri makanan air dalam kapas basah yang diletakkan di atas kain kasa penutup.

5). Dihitung jumlah nyamuk mati setelah 24 jam. Hasil penghitungan dimasukkan dalam tabel.

6). Apabila jumlah kematian nyamuk pada kelompok kontrol negatif kurang dari 5\% maka diabaikan, namun apabila lebih dari $20 \%$ maka uji harus diulang. Sedangkan apabila angka kematian nyamuk pada kelompok kontrol negatif 5-20\%, maka untuk menghitung persentase kematian nyamuk pada masing-masing konsentrasi dilakukan dengan formula Abot sebagai berikut :

$100 \times \frac{\% \text { KematianPerlakuan }-\% \text { KematianKontrol }}{100 \%-\text { KematianKontrol }}$

7). Langkah kerja (1) sampai dengan (7) diulangi pada konsentrasi yang berbeda dan hasil pengukuran direkap dalam tabel.

c. Setelah mendapatkan konsentrasi yang tepat dari uji pendahuluan, maka dapat dilanjutkan untuk uji yang sesungguhnya sesuai dengan cara yang di atas. 


\section{HASIL DAN PEMBAHASAN}

Hasil uji one way Anova jumlah kematian nyamuk Aedes aegypti pada taraf kepercayaan $\alpha$
$=0.05$ didapatkan nilai $\mathrm{F}$ hitung $(24,557)$ lebih besar dari $\mathrm{F}$ tabel $(0,05)$ sebagaimana disajikan pada Tabel 1.

Tabel 1. Jumlah kematian rata-rata nyamuk Aedes aegypti pada berbagai konsentrasi ekstrak buah Leunca (Solanum nigrum L.) dengan uji one way Anova.

\begin{tabular}{lrrrrr}
\hline & Sum of Squares & Df & Mean Square & F & \multicolumn{1}{c}{ Sig. } \\
\hline Between Groups & 1331.846 & 4 & 332.962 & 24.557 & .000 \\
Within Groups & 813.538 & 60 & 13.559 & & \\
\hline Total & 2145.385 & 64 & & &
\end{tabular}

Hasil uji one way Anova jumlah kematian nyamuk Anopheles aconitus pada tarafkepercayaan besar dari $\mathrm{F}$ tabel $(0,05)$ sebagaimana disajikan $\alpha=0,05$ didapatkan nilai $\mathrm{F}$ hitung $(33,794)$ lebih

Tabel 2. Hasil Analisis data kematian rata-rata nyamuk Anopheles aconitus pada berbagai konsentrasi ekstrak buah Leunca (Solanum nigrum L.) dengan uji one way Anova

\begin{tabular}{lrrrrr}
\hline & Sum of Squares & Df & Mean Square & F & Sig. \\
\hline Between Groups & 2203.015 & 4 & 550.754 & 33.794 & .000 \\
Within Groups & 977.846 & 60 & 16.297 & & \\
\hline Total & 3180.862 & 64 & & &
\end{tabular}

Untuk mengetahui lethal concentration maka dilakukan uji analisis probit dan didapatkan ekstrak yang digunakan dalam membunuh nyamuk hasil sebagaimana disajikan pada Tabel 3 dan 4.

Tabel 3. Hasil analisis probit $\mathrm{LC}_{50}$ Dan $\mathrm{LC}_{90}$ ekstrak buah Leunca (Solanum nigrum L.) terhadap kematian ratarata nyamuk Aedes aegypti

\begin{tabular}{ccc}
\hline $\mathrm{LC}$ & $\begin{array}{c}\text { Konsentrasi } \\
(\mathrm{gr} / 100 \mathrm{ml} \text { pelarut })\end{array}$ & Range \\
\hline $\mathrm{LC}_{50}$ & 91,128 & $69,890<\mathrm{LC}<156,417$ \\
$\mathrm{LC}_{90}$ & 785,398 & $337,934<\mathrm{LC}<5842,532$ \\
\hline
\end{tabular}

Tabel 4. Hasil analisis probit $\mathrm{LC}_{50}$ dan $\mathrm{LC}_{90}$ ekstrak buah Leunca (Solanum nigrum L.) terhadap kematian ratarata nyamuk Anopheles aconitus.

\begin{tabular}{ccc}
\hline LC & $\begin{array}{c}\text { Konsentrasi } \\
(\mathrm{gr} / 100 \mathrm{ml} \text { pelarut })\end{array}$ & Range \\
\hline $\mathrm{LC}_{50}$ & 24,767 & $19,809<\mathrm{LC}<33,570$ \\
$\mathrm{LC}_{90}$ & 169,046 & $96,540<\mathrm{LC}<450,875$ \\
\hline
\end{tabular}

Berdasarkan hasil penelitian, dapat diketahui bahwa ekstrak buah Leunca (Solanum nigrum L.) mempunyai pengaruh yang signifikan terhadap kematian nyamuk Aedes aegypti dan Anopheles aconitus. Secara garis besar, kenaikan konsentrasi ekstrak buah Leunca (Solanum nigrum L.) juga diikuti kenaikan jumlah kematian nyamuk sampai tingkat konsentrasi tertentu. Dari hasil penelitian juga dapat disimpulkan bahwa semakin besar konsentrasi ekstrak buah Leunca 
(Solanum nigrum L.) dan semakin lamanya kontak insektisida dengan nyamuk Aedes aegypti dan Anopheles aconitus maka semakin tinggi potensi insektisidanya.

Ekstrak buah Leunca (Solanum nigrum L.) memiliki kandungan senyawa kimia yaitu glikolkaloid yang berfungsi sebagai racun kontak pada nyamuk Aedes aegypti dan Anopheles aconitus. Kemampuan glikoalkaloid untuk mengikat denganmembran $3 \beta$-hidroksi sterol dapat mengakibatkan gangguan fungsi membran. Zat ini juga dapat menghambat kerja enzim asetilkolinesterase (Mohyuddin, 2009). Hal ini menyebabkan akumulasi asetilkolin dalam sistem saraf, sehingga akumulasi asetilkolin dapat mengakibatkan cacat pencernaan, gangguan saraf dan bahkan kematian (Gurbus, 2010).

Adapun jumlah kematian nyamuk Aedes aegypti dari tiap kelompok perlakuan beserta rataratanya disajikan pada Tabel 5 .

Tabel 5. Jumlah kematian nyamuk Aedes aegypti setelah diuji dengan ekstrak buah Leunca (Solanum nigrum L.) dalam berbagai konsentrasi selama 24 jam

\begin{tabular}{ccccccc}
\hline \multirow{2}{*}{ Ulangan } & \multicolumn{7}{c}{ Kelompok } \\
\cline { 2 - 7 } & I & II & III & IV & V & VI \\
& Aquades & $20 \%$ & $40 \%$ & $60 \%$ & $80 \%$ & Baygon \\
\hline 1 & 0 & 9 & 12 & 16 & 22 & 25 \\
2 & 0 & 10 & 13 & 17 & 23 & 25 \\
3 & 0 & 8 & 12 & 15 & 23 & 25 \\
4 & 0 & 9 & 13 & 15 & 24 & 25 \\
\hline Jumlah Kematian & 0 & 36 & 50 & 63 & 92 & 100 \\
Rata-rata & 0 & 9 & 13 & 16 & 23 & 25
\end{tabular}

Persentase kematian nyamuk Aedes aegypti dapat dilihat pada Grafik 1. pada berbagai konsentrasi ekstrak buah Leunca

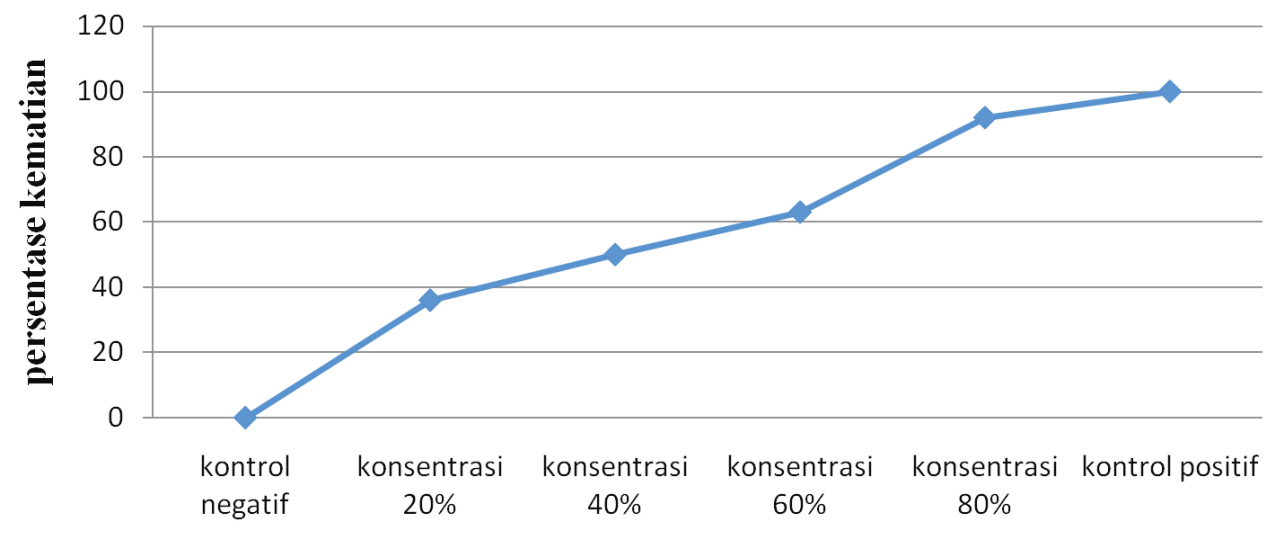

konsentrasi ekstrak buah leunca

Grafik 1. Grafik jumlah kematian nyamuk Aedes aegypti pada berbagai konsentrasi ekstrak buah Leunca (Solanum nigrum L.)

Sedangkan jumlah rata-rata kematian konsentrasi ekstrak disajikan pada Tabel 6 . nyamuk Anopheles aconitus pada berbagai 
Tabel 6. Jumlah kematian nyamuk Anopheles aconitus setelah diuji dengan ekstrak buah Leunca (Solanum nigrum L.) dalam berbagai konsentrasi selama 24 jam pada uji penelitian

\begin{tabular}{ccccccc}
\hline \multirow{2}{*}{ Ulangan } & \multicolumn{7}{c}{ Kelompok } \\
\cline { 2 - 7 } & I & II & III & IV & V & VI \\
& Aquades & $5 \%$ & $10 \%$ & $20 \%$ & $40 \%$ & Baygon \\
\hline 1 & 0 & 2 & 10 & 20 & 23 & 25 \\
2 & 0 & 11 & 11 & 21 & 22 & 25 \\
3 & 0 & 9 & 15 & 20 & 24 & 25 \\
4 & 0 & 10 & 18 & 20 & 25 & 25 \\
\hline Jumlah Kematian & 0 & 32 & 54 & 81 & 94 & 100 \\
Rata-rata & 0 & 8 & 14 & 20 & 24 & 25
\end{tabular}

Persentase kematian nyamuk Anopheles Leunca dapat dilihat pada Grafik 2. aconitus pada berbagai konsentrasi ekstrak buah

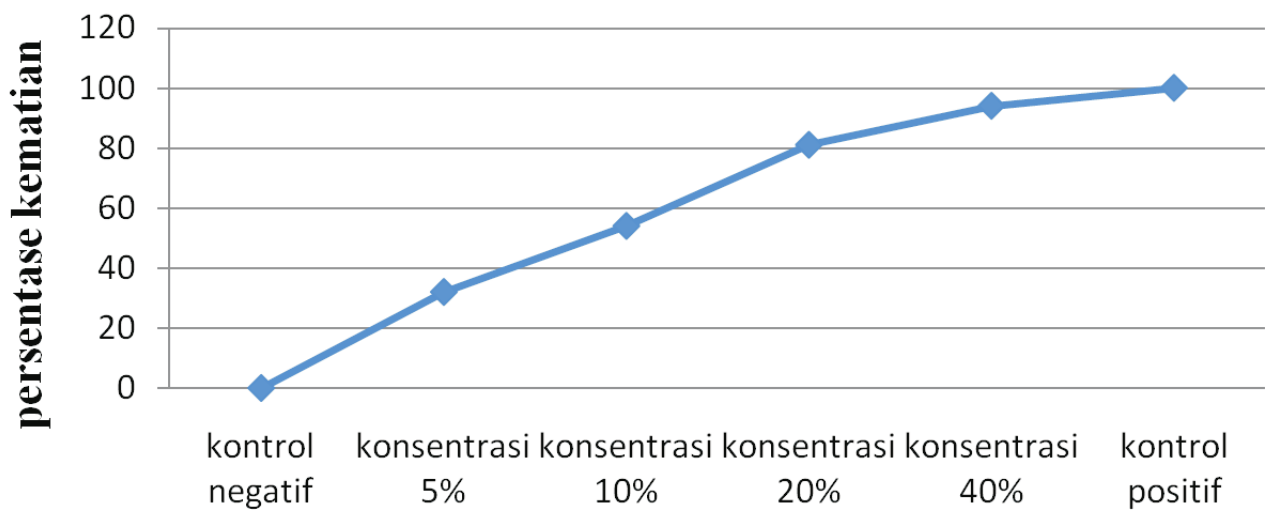

\section{konsentrasi ekstrak buah leunca}

Grafik 2. Grafik jumlah kematian nyamuk Anopheles aconitus pada berbagai konsentrasi ekstrak buah Leunca (Solanum nigrum L.)

Terdapat perbedaan jumlah zat aktif pada masing-masing konsentrasi ekstrak buah Leunca (Solanum nigrum L.) sehingga menyebabkan adanya perbedaan jumlah zat aktif yang mengenai masing-masing nyamuk saat penyemprotan. Pada hasil penelitian juga menunjukkan perbedaan antara konsentrasi yang digunakan dan jumlah kematiaan pada konsentrasi tertentu yang disemprotkan pada nyamuk Aedes aegypti dan Anopheles aconitus. Hal tersebut dapat terjadi karena adanya aktivitas enzim esterase yang terkait dengan mekanisme timbulnya resistensi pada nyamuk vektor terhadap insektisida. Peningkatan dari aktivitas enzim esterase dapat mencegah aksi dari insektisida dan mengakibatkan menurunnya dosis letal menjadi subletalnya, sehingga tidak lagi mematikan insekta yang menjadi sasaran (Lidia \& Setianingrum, 2008).
Timbulnya resistensi nyamuk terhadap insektisida dapat disebabkan karena penetrasi insektisida melalui kulit atau integumentum nyamuk berkurang, insektisida dimetabolisme oleh enzim esterase, mixed function oxidases atau glutathione transferase dan terjadinya penurunan kepekaan (insensitivitas) tempat sasaran insektisida pada tubuh nyamuk menurun seperti asetilkolinesterase (terhadap organofosfat dan karbamat), sistem syaraf (knock down resisten gen/Kdr) terhadap DDT (Dichloro Diphenyl Trichloroethane) dan pyrethroid atau sasaran insektisida mengalami modifikasi (Widiarti et.al, 2009).

Resistensi tersebut dapat disebabkan oleh beberapa faktor, yaitu faktor genetik, biologiekologi dan operasional. Faktor genetik yaitu frekuensi, jumlah dan dominansi alel resisten. 
Faktor biologi-ekologi meliputi perilaku nyamuk, jumlah generasi pertahun, mobilitas dan migrasi. Faktor operasional meliputi jenis dan sifat insektisida yang digunakan, jenis insektisida yang digunakan sebelumnya, persistensi, jumlah aplikasi dan stadium sasaran, dosis, frekuensi dan cara aplikasi, serta bentuk formulasi (Widiarti et.al, 2009).

\section{SIMPULAN}

1. Ekstrak buah Leunca (Solanum nigrum L.) memiliki efek insektisida terhadap nyamuk Aedes aegypti pada kelompok perlakuan dengan konsentrasi $80 \%$, dilihat dari hasil yang signifikan pada uji Oneway Anova yaitu dengan nilai $\mathrm{p}=0,000(\mathrm{p}<0,05)$ dan didapatkan $\mathrm{LC}_{50}$ pada konsentrasi 91,128 (gr/100ml pelarut) dan $\mathrm{LC}_{90}$ pada konsentrasi 785,398 (gr/100ml pelarut).

2. Ekstrak buah Leunca (Solanum nigrum L.) memiliki efek insektisida terhadap nyamuk Anopheles aconitus pada kelompok perlakuan dengan konsentrasi $40 \%$, dilihat dari hasil yang signifikan pada uji Oneway Anova yaitu dengan nilai $\mathrm{p}=0,000(\mathrm{p}<0,05)$ dan didapatkan $\mathrm{LC}_{50}$ pada konsentrasi 24,767 (gr/100ml pelarut) dan $\mathrm{LC}_{90}$ pada konsentrasi 169,046 (gr/100ml pelarut).

\section{SARAN}

1. Perlu adanya penelitian lebih lanjut terhadap pengaruh ekstrak buah Leunca (Solanum nigrum L.) terhadap kematian vektor-vektor penyakit yang lain sehingga pemanfaatan ekstrak buah Leunca (Solanum nigrum L.) dapat maksimal karena keunggulan ekstrak buah Leunca (Solanum nigrum L.) yang murah, aman dan mudah didapatkan di Indonesia.

2. Sebaiknya dilakukan penelitian lebih lanjut mengenai isolasi glikoalkaloid yang digunakan sebagai insektisida terhadap nyamuk Aedes aegypti dan dan Anopheles aconitus supaya didapatkan hasil yang lebih efektif.

3. Agar dilakukan penelitian lebih lanjut untuk menentukan formulasi ekstrak buah Leunca (Solanum nigrum L.) yang lebih praktis sehingga memudahkan dalam pendistribusiannya kepada masyarakat.

\section{DAFTAR PUSTAKA}

Astuti, E.P. 2008. Efektivitas Minyak Biji Kamadrah (Croton tiglium) dan Jarak Pagar (Jatropha curcas) sebagai Larvasida, Anti-oviposisi dan Ovisida Nyamuk Aedes aepypti dan Aedes albopictus. Institut Pertanian Bogor. Tesis.

Badan POM RI, 2008.Pencegahan Keracunan Racun Alami Dari Tanaman Pangan. Info POM. 9 (3): 5-7.

Depkes RI. 2013. Program Pengendalian Penyakit Capai Target. Direktur Jendral Pengendalian Penyakit dan Penyehatan Lingkungan. Diakses pada tanggal 26 Juni 2013 dari: http://www.depkes.go.id/index.php/berita/ press-release/2242-program-pengendalianpenyakit-capai-target.html.

Depkes RI. 2011. Pengendalian Malaria Masih Hadapi Tantangan. Diakses pada tanggal 26 Juni 2013 dari: http://www.depkes. go.id/index.php/berita/press-release/1488pengendalian-malaria-masih-hadapitantangan.html.

Dinkes Jawa Tengah. 2011. Data/Informasi Kesehatan Provinsi Jawa Tengah. Profil Kesehatan Provinsi Jawa Tengah Tahun 2011. Diakses pada tanggal 25 Juni 2013 dari: http://www. depkes.go.id/downloads/kunker/13 jateng. pdf

Freedman, D.O. 2008. Malaria Prevention in ShortTerm Travelers. N Engl J Med. 359:603-12.

Gurbus, N. 2010.Genetic Mapping and Characterization of Eggplant for Glycoalkaloid Content. The Graduate School of Engineering and Sciences of İzmir Institute of Technology. Tesis.

Hadi, U.K., Susi S. \& Dwi D. G. 2012. Aktivitas Nokturnal Vektor Demam Berdarah Dengue Di Beberapa Daerah Di Indonesia. Indonesia Journal of Entomology. 9 (1): 1-6.

Irwadi, D., M. Arif \& Hardjoeno. 2007. Gambaran Serologis IgM - IgG Cepat Dan Hematologi Rutin Penderita DBD. Indonesia Journal of Clinical Pathology and Medical Laboratory. 13 (2): 45-48.

Lailatul, L., Asep K. \& Ratnaningsih E. 2010. Efektifitas Biolarvasida Ekstrak Etanol Limbah Penyulingan Minyak Akar Wangi (Vetiveria zizanoides) terhadap Larva Nyamuk Aedes aegypti, Culek sp., dan Anopheles sundaicus. Jurnal Sains dan Teknologi Kimia. 1 (1): 59-65.

Lidia, K. \& Setianingrum E. L. S. 2008. Deteksi 
Dini Resistensi Nyamuk Aedes albopictus terhadap Insektisida Organofosfat di Daerah Endemis Demam Berdarah Dengue di Pulu (Sulawesi Tengah). Media Kesehatan Masyarakat. 3 (2): 105-110.

Mohyuddin, A. 2009. Chemotaxonomical Characterization of Solanum nigrum L. and its Varieties. Pakistan: Department of Chemistry, GC University Lahore.
Widiarti, Suskamdani \& Mujiono. 2009. Resistensi Vektor Malaria terhadap Insektisida di Dusun Karyasari dan Tukatpule Pulau Bali dan Desa Lendang Ree dan Labuhan Haji Pulau Lombok. Media Penelitian dan Pengembangan Kesehatan. 19 (3): 154-164. 